\title{
O caderno de sabatinas: uma proposta de análise sobre culturas e práticas escolares do Colégio Nossa Senhora de Lourdes, Farroupilha (Rio Grande do Sul/Brasil)
}

\author{
Evaluation notebook: a proposal of analysis about cultures and school practices \\ of Nossa Senhora de Lourdes School, Farroupilha/RS/Brazil
}

El cuaderno de pruebas: Una propuesta de análisis sobre culturas y prácticas escolares del Colegio Nuestra Señora de Lourdes, Farroupilha/RS/Brasil

\section{GiSElE BELUSSO ${ }^{1}$; TERCIANE ÂNGELA LUCHESE ${ }^{2}$}

\section{Resumo}

O presente artigo comunica resultados de pesquisa na temática da História da Educação, atentando para o processo histórico do Colégio Nossa Senhora de Lourdes, Farroupilha/RS (1922-1954). Nesse sentido, tem como objetivo analisar indícios das culturas e práticas escolares a partir da cultura material. Para tanto, utilizou-se, principalmente, um caderno de sabatinas e também outros documentos, tais como o livro de atas de comemorações cívicas, livros de chamada, legislação vigente e memórias de ex-alunos e ex-professoras-religiosas. $\mathrm{O}$ aporte teórico é o da História Cultural e, como metodologia, foi utilizada a análise documental e a história oral. A análise permitiu perceber elementos das culturas e práticas escolares que permearam o cotidiano do Colégio Nossa Senhora de Lourdes, no ensino primário, na década de 40 do século XX.

Palavras-chave: Práticas escolares. História das instituições. Ensino Primário.

\footnotetext{
${ }^{1}$ Doutoranda em Educação no Programa de Pós-Graduação em Educação da Universidade de Caxias do Sul. Bolsista Capes. Membro do Grupo de Pesquisa História da Educação, Imigração e Memória. E-mail: giselebelusso@hotmail.com

${ }^{2}$ Doutora em Educação pela Universidade do Vale do Rio dos Sinos. Professora do Programa de PósGraduação em História e do Programa de Pós-Graduação em Educação da Universidade de Caxias do Sul. Líder do Grupo de Pesquisa História da Educação, Imigração e Memória. Bolsista de Produtividade em Pesquisa do CNPq. E-mail: taluches@ucs.br
} 


\begin{abstract}
This article presents research results within the subject History of Education, paying attention to the historic process of Nossa Senhora de Lourdes School, Farroupilha/RS (1922-1954). In this sense, its objective is to analyze signs of culture and school practices from material culture. For this, an evaluation notebook and other documents were mainly used, as well as a minute book of civic commemorations, roll call books, existing legislation and memories of exstudents and ex-teachers-Sisters. The theoretical contribution is that of Cultural History, and, as methodology, the document analysis and oral history were used. The analysis allowed noting elements of school cultures and practices that permeated Nossa Senhora de Lourdes School daily routine, in primary school, in the forties of the twentieth century.
\end{abstract}

Key words: School practices. History of institutions. Primary teaching.

\title{
Resumen
}

Este artículo comunica resultados de investigación en la temática de la Historia de la Educación, atentando para el proceso histórico del Colegio Nossa Senhora de Lourdes, Farroupilha/RS (1922-1954). En este sentido, tiene por objetivo analizar indicios de las culturas y prácticas escolares a partir de la cultura material. Para tanto, se utilizó, principalmente, un cuaderno de pruebas y también otros documentos, tales como el libro de actas de conmemoraciones cívicas, libros de presencias, legislación vigente y memorias de ex-alumnos y ex-maestras religiosas. El aporte teórico es el de la Historia Cultural y, como metodología, fue utilizado el análisis documentario y la historia oral. El análisis permitió descubrir elementos de las culturas y prácticas escolares que permearon el cotidiano del Colegio Nossa Senhora de Lourdes, en la enseñanza primaria, en la década del 40 del siglo XX.

Palabras clave: Prácticas escolares. Historia de las instituciones. Enseñanza Primaria. 


\section{Considerações iniciais}

Com a invenção da escola moderna, a necessidade e a exigência legal da escrituração escolar, novos objetos passaram a fazer parte do seu cotidiano, como o uso de livros de atas, livros de registro para a frequência escolar, cadernos, canetas, livros, entre outros, em substituição a objetos, como, por exemplo, ardósias e tinteiros - o que oportuniza, atualmente, a busca por registros escolares nos arquivos das próprias instituições, mas também amplia a possibilidade de pesquisar em acervos pessoais ${ }^{3}$ de professores e alunos, que frequentaram as instituições escolares, em busca de objetos da cultura material escolar.

Nas pesquisas em História da Educação, no eixo das instituições escolares, com o foco de análise nas culturas e práticas escolares, tem sido cada vez mais frequente a utilização de novas fontes oriundas de acervos pessoais, o que se potencializa com a utilização da história oral enquanto metodologia em conjunto com os pressupostos teóricos da História Cultural. Foi o que ocorreu também durante a pesquisa sobre o processo histórico do Colégio Nossa Senhora de Lourdes.

Os documentos analisados, exceto o caderno de sabatinas advindo de um acervo pessoal, fazem parte do arquivo escolar do Colégio Nossa Senhora de Lourdes, e as memórias utilizadas compõem um conjunto de oito narrativas de sujeitos que são ex-alunos e ex-professoras-religiosas e que fizeram parte do processo histórico da instituição no período delimitado para pesquisa ${ }^{4}$.

A análise aqui proposta considera como pressuposto que cada instituição escolar tem uma cultura escolar própria em que convivem diversas "culturas", compreendidas a partir de como Viñao Frago nos sinaliza:

Y si, es cierto, la cultura escolar es toda la vida escolar: hechos e ideas, mentes y cuerpos, objectos e conductas, modos de pensar, decir y hacer. Lo que sucede es que en conjunto hay algunos aspectos que son más relevantes que otros, e nel sentido que son elementos organizadores que la conforman e definen (VIÑAO FRAGO, 1995, p. 69). ${ }^{5}$

E, a partir dessa perspectiva, adota-se o conceito de culturas escolares reconhecendo o amplo leque e a potencialidade que se abre na operacionalização da investigação que adentra o interior da instituição escolar, perscrutando suas culturas. As práticas escolares, por sua vez, nesse contexto, são vistas como algo que acontece na escola, porém deixa poucos vestígios, "o que é invocado, mas ausente, é o que se faz na escola, o que se faz hoje ou o que é sempre feito, enfim, a prática escolar"(CHARTIER, 2000, p.158), considerada pela autora como os fazeres ordinários.

\footnotetext{
${ }^{3}$ Sobre acervos pessoais de educadores ver Cunha (2016), trabalho encomendado para o eixo 1, História da Educação, da XI Reunião Científica da ANPED sul.

${ }^{4}$ Os nomes aqui citados são identificados por opção dos entrevistados que assim autorizaram no Termo de Consentimento Livre e Esclarecido.

${ }^{5}$ Alguém dirá: tudo. Sim, é certo, a cultura escolar é toda a vida escolar: acontecimentos e ideias, mentes e corpos, objetos e condutas, modos de pensar, dizer e fazer. O que acontece é que, em conjunto, existem alguns aspectos que são mais relevantes que outros, é nesse sentido que são elementos organizadores que a conformam e a definem. (Tradução livre da autora).
} 
Ciente da complexidade de tais conceitos, o presente artigo tem como objetivo analisar indícios das culturas e práticas escolares a partir, principalmente, de um caderno de sabatinas do ensino primário do Colégio Nossa Senhora de Lourdes, compreendendo que a cultura material ${ }^{6}$ é elemento constitutivo das práticas escolares (VIDAL, 2009).

Os cadernos escolares podem ser fonte histórica para compreender não só as culturas escolares, a transmissão de valores e modos de pensar, mas também a história do currículo, a cultura da escrita, as reformas e as inovações educativas. (VIÑAO, 2008). E, nesse tocante, o caderno escolar pode ser analisado por diferentes perspectivas, e pode ser portador de vários sentidos: "como escritas ordinárias, testemunhos de uma construção de si; relíquias conectadas com uma sensibilidade nostálgica[...]” (CUNHA, 2015, p.13). Ou pode, ainda, depor

[...]sobre uma pluralidade de significações: orientação do ato educativo, em que se captam objetivos políticos e sociais, além de teorias pedagógicas, relação-discípulo no quadro da sala de aula, estética da ilustração dos modelos de escrita e, finalmente, as interfaces econômicas, designadamente comerciais que lhe suportavam a difusão ou decorriam dela (FERNANDES, 2008, p. 50-51).

Neste artigo, optamos por enfocar a análise pelo viés das culturas e dos valores que permearam as práticas escolares em voga na instituição no período. Mogarro (2010) refere que "a cultura material é parte integrante da cultura escolar, e coloca os espaços educativos, os edifícios escolares, o mobiliário e os materiais de ensino na agenda de investigação, como objeto de estudo fundamental para a compreensão dos processos educativos e das práticas de ensino" (MOGARRO, 2010, p.92). Desse modo, o caderno pode ser pensado como "portador de sentidos ligados ao sistema de valores e representações sociais que ultrapassam a função de objeto destinado, somente, ao registro do processo de aprendizagem" (CORDOVA, 2016, p. 209).

Tal perspectiva incita a reflexão sobre o uso do caderno de sabatinas eleito como documento e, desse modo, questionado, perscrutado, escrutinado por nossas questões de pesquisa, considera-se que, ao utilizar o mesmo, tenha ocorrido uma intencionalidade e uma forma ritualizada de realizar as sabatinas em questão, em que é necessário considerar a oralidade, o gestual e as táticas que podem ter sido utilizadas pela aluna. Podem ser considerados exemplos de táticas a forma de utilizar o espaço na folha de papel, o pequeno desenho de uma flor ou até mesmo alguma ausência ou acréscimo que não seja possível identificar na escrita, pois extrapolariam a possibilidade normatizada/ritualizada do registro escrito (CERTEAU, 1994).

Ainda nesse sentido, Meneses (1998, p.95) afirma que "toda operação com documentos, portanto, é de natureza retórica”. Assim, acrescentaríamos que se refere à retórica do dito e do não dito, ao passo que o caderno traz marcas de registro que sinalizam posições em um quadro social (MENESES, 1998), aproximações que se referem as práticas de escrita, aos valores em voga na instituição; porém, também é preciso considerar que omite situações tais como: os acordos feitos por meio da oralidade, as formas de apropriação dos alunos e professores, o tempo dedicado àquela atividade, ou, ainda, não revela as, já citadas, formas criativas e inventivas de utilização (CERTEAU, 1994). Portanto, ao fazer uso do caderno como documento, reafirmamos que se deve considerar os ditos e não ditos.

\footnotetext{
${ }^{6}$ Sobre história da cultura material escolar ver Souza (2007).
} 
Os cadernos escolares passam a fazer parte do cotidiano escolar das escolas brasileiras no final do século XIX, início do século XX, e esse material escolar "alcançou status de principal suporte de escrita escolar" (CORDOVA, 2016, p. 218). O mesmo foi adequado para a organização das práticas escolares e como uma forma de racionalizar o ensino em tempos e espaços que compõem o caderno.

O caderno de sabatinas, principal fonte de análise para este artigo, foi utilizado no ensino primário, provavelmente na década de 40 do século XX, no Colégio Nossa Senhora de Lourdes. Essa é uma dentre as várias iniciativas de escolarização abertas pelas Irmãs Scalabrinianas no Rio Grande do $\mathrm{Sul}^{7}$. Desde o final do século XIX, diversas congregações religiosas chegaram ao Rio Grande do Sul e abriram escolas com o intuito de garantir a oferta do ensino privado e também do ensino religioso (GIOLO, 1997). Como reflexo desse processo, a Congregação das Irmãs Missionárias de São Carlos Borromeo Scalabrinianas ${ }^{8}$ foi uma das comunidades religiosas que abriu escolas no Estado.

A instituição foi aberta em 1917, em Farroupilha/RS, por quatro integrantes da Congregação, para ofertar o ensino primário, atendendo meninos e meninas. É privada, confessional e mantém-se em funcionamento, comemorando, em 2017, seu centenário. O surgimento da instituição está vinculado a solicitação dela pela comunidade em um território predominantemente de imigração italiana. Destaco que esse território inicialmente foi a Vila de Nova Vicenza, pertencente ao município de Caxias e que a partir de 1934 passou a ser município, então nomeado de Farroupilha/ $\mathrm{RS}^{9}$.

A instituição passou por algumas mudanças de endereço, até a construção de um prédio próprio, de alvenaria, inaugurado em 1943, com diferentes espaços, salas temáticas, como, por exemplo, sala de Geografia, História, Ciências Naturais, Música e Desenho. No decorrer de seu processo histórico, foi gradativamente ampliando o atendimento, com o jardim de infância, o curso de datilografia e o curso ginasial feminino, autorizado a funcionar em 1954. O corpo docente era formado predominantemente por irmãs, com exceções como o pároco e o militar que auxiliaram na tarefa da docência nas aulas de religião e educação física.

Considera-se que o Colégio Nossa Senhora de Lourdes, por se tratar de uma instituição confessional, com a docência realizada por professoras-religiosas e fortemente pautada nos valores religiosos e disciplinares, tem essas características, o que se pode atribuir à formação inicial docente: o noviciado, também realizada fortemente pautada na formação disciplinar.

Ao realizar a análise sob o viés das práticas escolares, foi possível auferir que no cotidiano do Colégio Nossa Senhora de Lourdes destacaram-se as práticas de leitura e escrita como pontos-chaves no Ensino Primário enquanto atividades norteadoras para o ensino dos demais saberes. Pode-se verificar no ensino de diferentes saberes a utilização de produções de desenhos, frases, redações, poesias, ditados, cópias, leituras e declamações, tanto no cotidiano da sala de aula, quanto nas lições de casa e nas comemorações escolares.

Outro aspecto destacado foi a ordem e disciplina como condutores das formas de organizar os tempos, espaços e práticas escolares da instituição. Esses elementos foram reiterados em cada entrevista efetuada com os ex-alunos e ex-professoras, assim, sendo considerados características da instituição de ensino juntamente aos valores permeados pela religião católica e pela exaltação à Pátria.

\footnotetext{
${ }^{7}$ Ver Belusso (2016).

${ }^{8}$ Sobre o processo histórico da congregação ver Signor $(2005 ; 2007)$.

${ }^{9}$ Sobre a emancipação ver Trentin (2002).
} 
A disciplina permeou a cobrança de questões como a pontualidade, o uso do uniforme escolar, o comportamento dentro e fora da instituição escolar, os corpos disciplinados, os momentos de oração. Além das orações, os cantos foram uma prática recorrente, tanto nas comemorações quanto nas festividades cívicas, nas atividades religiosas e também como forma de ensinar saberes. Descortina-se, assim, algumas das possibilidades de análise das culturas e práticas escolares dessa instituição.

O projeto sócio pastoral scalabriniano e a educação Scalabriniana já incitaram a atenção de alguns pesquisadores, dentre eles Signor (1984), Souza (2000), Bresolin (1998) e Nazario (2011), porém esses estudos não se referem especificamente a instituições escolares. Já no caso de pesquisadoras como Di Siervi (2002), Oliveira (2003) e Paz (2013), as pesquisas são específicas sobre instituições escolares scalabrinianas, sendo elas, respectivamente: o Orfanato Cristóvão Colombo, São Paulo; o Colégio Santa Teresa de Ituitaba, Minas Gerais e o Colégio São Carlos, Rio Grande do Sul, respectivamente. A pesquisadora Oliveira (2009) ainda ampliou sua pesquisa na tese de doutorado, voltando seu olhar para a Educação Scalabriniana no Brasil $^{10}$. O presente estudo, em conjunto com o das instituições escolares (PAZ, 2013; BELUSSO, 2016), poderá contribuir de maneira significativa na compreensão da atuação no campo educacional da Congregação das Irmãs Missionárias de São Carlos Borromeo Scalabrinianas, em especial no Rio Grande do Sul, e como apropriaram-se da tarefa de ensinar em suas iniciativas educacionais. Tais pesquisas analisam com diferentes enfoques documentos da congregação, das instituições escolares, memórias de professoras e acervos pessoais. A seguir, focamos a análise no caderno de sabatinas.

\section{Os registros da aprendizagem escolar: o caderno de sabatinas}

O termo sabatina, encontrado no Ratio Studiorum, método pedagógico dos Jesuítas publicado em 1599, é muito próximo daquele que localizamos na década de 40 do século XX, também utilizado no Rio Grande do Sul na instituição de ensino pesquisada. Isso não significa que acreditemos que o uso é o mesmo, pois as apropriações dos sujeitos em cada instituição são criadoras de usos e representações (CHARTIER, 2002), o que se pontua é a manutenção do termo "sabatina" para identificar um caderno utilizado para algumas avaliações, uma forma de organizar o cotidiano escolar, a qual pressupõe a utilização de outros cadernos. Os alunos, em entrevista, recordam da utilização de cadernos tais como de caligrafia e de desenho, além de livros que eram de leitura e não contemplavam espaços para escrita. (RASERA, 2015; TARTAROTTI, 2015; NORO, 2015).

Os cadernos escolares têm sido fonte para pesquisadores em história da educação (HÉRBRARD, 2001; CHARTIER, 2007; MIGNOT, 2008; FONSECA, et al., 2014) e oportunizam a análise por uma perspectiva diferente da encontrada nos documentos oficiais do arquivo escolar que contempla, no caso do Colégio Nossa Senhora de Lourdes, no período em questão, o registro de notas por disciplinas do currículo (LIVRO DE ATAS - EXAMES ESCOLARES). A nota em si, apenas um número, não traz consigo indícios das práticas escolares realizadas para avaliar, o que o caderno de sabatinas, por sua vez, nos traz.

10 Atualmente está sendo desenvolvida uma tese de doutoramento, no Programa de Pós-Graduação em Educação da Universidade de Caxias do Sul, pela pesquisadora Marina Matiello, a qual pretende analisar como se constituiu a educação carlista-scalabriniana no Rio Grande do Sul, no período de 1915 a 1966, desde a perspectiva da relação religiosidade/ escolarização/etnicidade. 
A ausência desse documento se deve pela sua falta de conservação na contemporaneidade. Com espaços cada vez menores nas residências, a tendência tem sido o descarte, como recorda Alice Noro: "Tinha, tinha cadernos, livros, até eu tinha até bem pouco tempo atrás até te disse tinha lá coisas minhas da minha irmã, do outro meu irmão, mas depois tive que dar cabo[...]" (NORO, 2015).

Assim como Alice Noro, os demais entrevistados descartaram a grande maioria de seus objetos escolares, restando ainda poucos documentos ${ }^{11}$, dentre eles o caderno de sabatinas. Por questões como essa, os cadernos escolares são raramente utilizados em pesquisas, porém concordamos com Chartier (2007, p.13) de que "eles fornecem, entretanto, testemunhos insubstituíveis a respeito dos exercícios escolares, das práticas pedagógicas e do desempenho dos alunos no contexto da sala de aula."

O caderno em questão faz parte do acervo pessoal de Odete Rasera, natural de Castro Alves/RS, nascida em primeiro de outubro de 1937. Ela cursou o ensino primário na instituição: “estudei só até a quarta. [...] eu não tenho muito estudo. É que naquela época era só meu pai que trabalhava e ele tinha sete filhos e quatro moças e tudo estudava, então, aqui ele botou nós sempre no Colégio das Irmãs.” (RASERA, 2015).

Com relação aos aspectos físicos, o caderno é tipo brochura, pequeno, tem 29 páginas, compostas por folhas escritas frente e verso, e a caligrafia é em letra cursiva. Apesar de no caderno não constarem datas, foi possível verificar que o mesmo é da década de 40 do século XX, a partir do livro de chamada da instituição. No mesmo, a aluna está registrada com o nome de solteira, Odete Zanco, no ano de 1947, cursando na época o segundo ano do primário e tendo como docente responsável da turma a professora Irmã Maria Fandila (CADERNO DE CHAMADAS, 1947).

Como a aluna refere-se acima, cursou o primário até a quarta série. Pressupõe-se, portanto, que o caderno ora analisado tenha sido utilizado até no máximo no ano de 1949, já que na mesma entrevista não citou reprovações, o que nos remete a um objeto escolar utilizado em torno de sessenta anos atrás.

A aluna conservou seu caderno das sabatinas, mesmo faltando algumas folhas, com pequenos rasgos e sem a capa, em que constam seis registros de notas escritos em outra cor, difícil de definir a tonalidade devido ao tempo e até mesmo se foi realizada com lápis ou caneta tinteiro ou esferográfica, como recorda a aluna "é a nota da professora!" (RASERA, 2015), referindo-se ser a mesma escrita por ela no caderno da aluna.

\footnotetext{
${ }^{11}$ Ainda foi possível acessar um caderno de desenho, certificados de conclusão, atividades do jardim de infância, boletins, uma medalha de reconhecimento pelas melhores notas de concluinte do primário, diversas fotografias e um livro de história e geografia em diferentes acervos pessoais dos entrevistados.
} 
Figura 1 - Marcas de registro de nota e correções ortográficas.

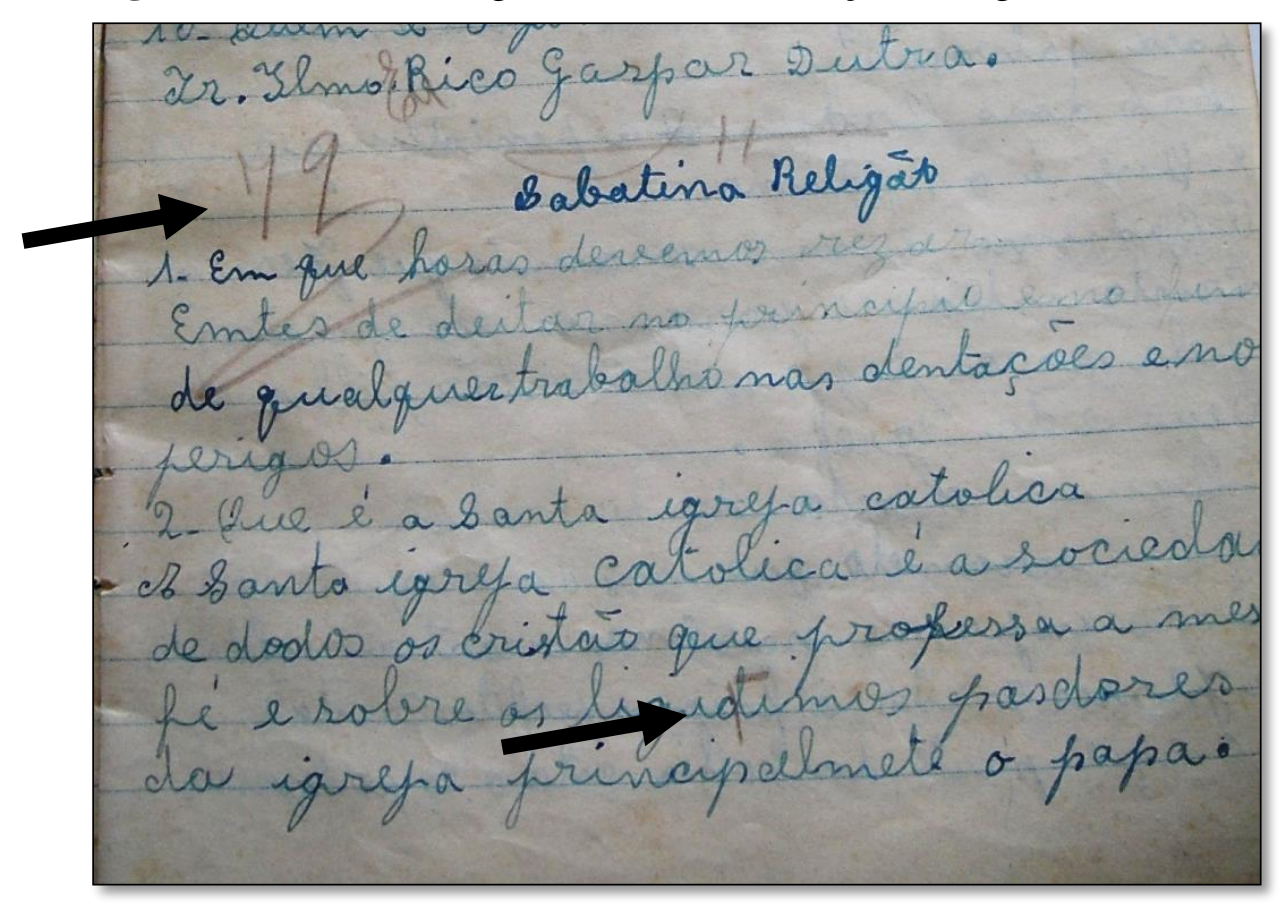

Fonte: Acervo pessoal de Odete Rasera.

Observa-se, ainda, na imagem (fig.1) marcas de correções ortográficas (apontadas pelas setas) sobre a escrita. E, mesmo ao não se distinguir a cor exata, é relevante observar que é diferente à da aluna, o que destaca na percepção visual a nota e as correções. A imagem parcial de uma das avaliações que se pode ver nessa imagem é sobre religião, mas versam também ao longo do caderno sobre conjugação verbal, análise gramatical, ditado, redação, lições de geografia, de civismo e de ciências. Não constam nesse caderno avaliações de matemática, o que suscita o questionamento de como eram realizadas, talvez, em outro caderno ou outro suporte.

Ao perceber as manifestações textuais como ditados e redações, pode-se sinalizar as mesmas como "marcas das práticas de escrita" as quais circularam nessa instituição escolar, dentre tantas outras que possam ter sido utilizadas. (CORDOVA, 2016, p.218).

Com relação especificamente aos ditados, têm como temas a vida saudável, o Brasil e as profissões. Anne Marie Chartier (2010), ao tratar sobre o ditado, destaca que o mesmo foi alvo de críticas por se tratar de um exercício de avaliação e não de aprendizagem, mas o que não levaram em consideração foi que "durante um ditado, todos os alunos se calam, escrevem todos sob a vista do professor, estão atentos a sua própria tarefa, e a correção, que vem logo em seguida, permite a cada um verificar o resultado de seu esforço." (CHARTIER, 2010, p.7-8). Portanto, tem um modo de ser executado, em que o silêncio é necessário, e que facilmente pode ser realizado por até mesmo um professor principiante.

Os aspectos destacados por Anne Marie-Chartier vêm ao encontro das análises acerca do caderno de sabatinas, tais como, o exercício do ditado aqui surge como forma de avaliar. Outro aspecto é de que, no decorrer da pesquisa, a ordem e a disciplina foram citadas como características da instituição pelos ex-alunos entrevistados, em que o silêncio foi considerado necessário para o ensinar e o aprender com qualidade. 
Tal afirmação se deve à representação, por exemplo, que a aluna Alice T. Noro (2015) referiu sobre a "conversa" em sala de aula: "o que tinha problema maior é de conversa". A partir desse ponto de vista, portanto, as formas de disciplinar são consideradas necessárias para um ensino de qualidade. É assim também que se refere o aluno Dino quando recorda da dedicação das Irmãs:

O respeito na aula era todo mundo silêncio [...]! Então a professora falava e dava os temas e tudo, todo mundo respeitava e todo mundo respeitava direitinho. A gente aprendeu muito, estudava bastante, era com muita disciplina e as aulas era tudo com bastante disciplina, a gente respeitava as professoras na aula". (Dino José Dorigon, 2016) (grifo da autora).

Nessa perspectiva, o ditado é uma atividade que necessita de silêncio para ser realizada e, portanto, trata-se de uma atividade adequada, pela postura cobrada dos alunos, ao processo de ensino e aprendizagem. Diante do exposto, entende-se que o exercício nos traz indícios da prática escolar, mas também das culturas escolares dessa instituição escolar em que está implícito um comportamento esperado por parte dos alunos.

Ao tratar do ditado em específico com o tema "vida saudável”, observa-se que o mesmo aborda aspectos da alimentação, da higiene corporal, que deve ser preservada com o banho diário e com hábitos como o de lavar as mãos antes das refeições, cortar e limpar as unhas e também de escovar os dentes após as refeições. Após abordar os aspectos de higiene corporal, aponta a importância da higiene na residência. Para facilitar a leitura, neste excerto não utilizo a imagem e sim a transcrição literal.

Para ter saúde, basta um boa alimetação! Perguntou Julinho. - Não, meu filhio, respondeu D. Lúcia. São necessários ainda outras. Em primeiro lugar, é presico asseio ou limpeza do corpo. Devemos para isso, tomar banho todos os dias, Escovar ors dentes pela manhã á noite e depois das refeisões; lavar as mãs antes de comer; cortar e limpar as unhas; E antar sempre limpo. Mas não basta tratar o asseio de nosso corpo, é preciso também cuitar da limpeza de nossa casa. Devemos tela sempre limpa e arrumada. Todo dia a poeira deve ser cuidadosamente varrida. E as moscas e as baratas e os ratos deve ser cotatidos. Eles transportam bicinhos chamado micróbios que produzem doenças. - Sabe quais os maiores amigos da saúde! - Sei D.Lucia. São o ar e o sol. Muito bem? Juliho. (CADERNO DE SABATINA).

O texto é um diálogo, e a aluna faz uso de sinais de pontuação - seria interessante saber se foram também ditados ou se foram inseridos na escrita de maneira espontânea a partir da entonação da voz da professora. Isso nos remete a outra reflexão: mesmo com um registro das práticas escolares, ele não nos oportuniza perceber os acordos realizados na oralidade entre alunos e professores, "nem tudo está nos cadernos. Eles silenciam, não dizem nada sobre as intervenções orais ou gestuais do professor e dos alunos[...]". (VIÑAO, 2008, p. 25).

Com relação à ortografia, equívocos podem ser observados, como, por exemplo, o título escrito "vida saida". Cogitam-se hipóteses de o título referir-se à vida saudável ou vida sadia. Ao analisar o texto, observamos que algumas palavras estão marcadas por reescritas, ou de letras ou de sílabas, o que indica que não era possível apagar. No quadro a seguir, listam-se os erros ortográficos identificados. 
Quadro 1 -1 Escrita e hipóteses de escrita - ditado

\begin{tabular}{|c|c|}
\hline Escrita encontrada no ditado & Hipótese de escrita ortograficamente correta \\
\hline Alimetação & Alimentação \\
\hline Filhio & Filho \\
\hline Presico & Preciso \\
\hline Manhão & Manhã \\
\hline Refeisões & Refeições \\
\hline Antar & Andar \\
\hline Arumada & Arrumada \\
\hline Cotatidos & Combatidos \\
\hline Bicinhos & Bichinhos \\
\hline Juliho & Julinho \\
\hline
\end{tabular}

Fonte: Caderno de sabatinas, acervo pessoal de Odete Rasera.

Notam-se questões ortográficas relacionadas à omissão e troca de letras (c por s, ç por $\mathrm{s}, \mathrm{d}$ por $\mathrm{t}$ ). A noção do $\mathrm{lh}$ e ch ainda não fora adquirida pela aluna. Pelo caderno não temos como auferir as marcas na oralidade decorrentes da aprendizagem em família do dialeto vêneto sul-rio-grandense, distinção cultural relevante da região. Para além das marcas de sotaque e alternância de códigos presentes na oralidade, a transposição do falado para o escrito parece ter induzido a alguns dos erros registrados no ditado feito por Odete ${ }^{12}$. Embora a letra seja legível e clara, a aluna, ao referir-se a sua letra durante a entrevista, a representa justificando: "só que eu tenho a letra meia feia". (Odete Rasera, 2015). Tal afirmação demonstra que havia a preocupação com a caligrafia, e essa fazia parte das práticas no ensino da escrita. Os ex-alunos recordaram de que "caligrafia se fazia muito, sim!” (Dino José Dorigon, 2016). Porém não foi possível, durante as entrevistas, saber detalhes que revelassem a forma como se ensinava/aprendia a caligrafia na escola. Somente se soube que era uma atividade realizada com frequência. Independente dos modelos ou métodos de ensinar caligrafia, observa-se que os mesmos tiveram como justificativa a saúde das crianças, porém somente o movimento muscular ${ }^{13}$ advogou com uma base teórica (VIDAL; ESTEVES, 2003).

O ditado, não por acaso, constitui-se de um diálogo de uma mãe com seu filho, considerando-se que se trata de uma escola que tem em sua maioria alunas meninas e, portanto, na época, responsáveis em preservar determinados valores familiares. As respostas enfatizam a higiene pessoal e também o cuidado com a casa, sua organização, limpeza e ventilação. Os conhecimentos de higiene no ensino primário abarcavam aspectos imbuídos de valores e condutas, "as primeiras lições deveriam recair sobre o cuidado pessoal, seguido da alimentação, do vestuário e da habitação, incluindo os efeitos nocivos do tabaco e do álcool”. (SOUZA, 2009, p.32). O referido ditado é seguido de uma análise gramatical dos termos do texto, e a nota (70) setenta, ao que parece, é atribuída ao conjunto (ditado e análise gramatical).

\footnotetext{
${ }^{12}$ Sobre o contato entre línguas e o bilinguismo na Região Colonial Italiana ver os estudos de Frosi e Mioranza (1983; 2009) e Faggion e Luchese (2011).

${ }^{13}$ Embasava-se na fisiologia dos movimentos dos olhos, dos braços e das mãos. Buscavam uma escrita mais ágil e eficiente que as antecedentes, ao mesmo tempo em que desejavam alargar a habilidade do escrever com as duas mãos (VIDAL; ESTEVES, 2003, p. 133).
} 
Outro tema explorado, nos ditados do caderno de sabatinas de Odete, foi o Brasil. O ditado transcrito abaixo intitula-se "Nosso Brasil".

Tudo o que existe no nosso Brasil é grande e belo. O solo é cheio de riquezas o clima sadio e agradável. As florestas são imensas e verdejantes. As cachoeiras são lindas e poderosas. A terra é fértil e colhedora [sic]. Mas o que torna o nosso Brasil mais dignos [sic] de admiração é o trabalho dos seus filhos. São suas cidades lindas e progressistas. São as fábricas que produzem tudo. São os navios sulcando os mares. São os tormes [sic] de ferro correndo pelos trilhos. São os aviões cortando o espaço, são as escolas ensinando as crianças amar e respeitar o Brasil. Devemos estudar e trabalhar para que nossa Pátria fique cada vez mais bela, mais rica e mais livre! Estudando e trabalhando, sob este céu de anil. As crianças vão fazer a grandeza do Brasil! (CADERNO DE SABATINAS).

A exaltação ao nacional fica evidente na escrita, bem como a valorização dos recursos naturais, do trabalho, da industrialização de uma nação em progresso, do desenvolvimento dos transportes marítimos, terrestres e aéreos. Também enaltece o papel da escola na formação do povo brasileiro na perspectiva de formar cidadãos para o futuro da Pátria. Os conhecimentos de cunho moral, cívico, religioso, higiênico e naturalista são considerados por Peres (2016, p.38) como "grandes articulares do discurso regulativo", ou seja, do Decreto 8.020 de 29/11/1939.

O texto ditado pela professora contempla o esperado, inclusive para matérias como Geografia, História, Educação Física, Instrução Moral e Cívica, as quais deveriam “desenvolver nas crianças o espírito de patriotismo e nacionalismo; deveriam contribuir para a formação moral do povo e, no limite, para a construção da nacionalidade. Essa ênfase no nacionalismo atravessou o século XX”. (SOUZA, 2009, p. 113).

O que também fora observado na sabatina de civismo é que as questões versavam sobre o funcionário público, os impostos e sua utilização; sobre a postura que se deve ter na rua, sobre o País, o Estado e o nome do governador. Observa-se que os textos referiamse a comportamentos, até aqueles fora do ambiente escolar, como observa-se a seguir: "[...] Como devemos andar na rua. Andar com passos moderados não esbarar[sic] nem acotovelar ninguém si [sic] o fizer por descuido imediatamente pedir desculpa." (CADERNO DE SABATINAS). O caminhar na rua também foi questão de uma das sabatinas avaliadas, o ritmo ideal dos passos e, ainda, em caso de descuido "acotovelar alguém", o comportamento esperado é que se peça desculpas imediatamente. Julia (2001) argumenta que a cultura escolar compreende hábitos a ensinar e comportamentos a inculcar. Como destacam Arriada e Tambara (2012, p. 74), não se pode desconsiderar que a escola foi base para os sistemas públicos de educação e que "se tratava não apenas de um modelo de escola que instruía e formava, mas também estabelecia valores, que se articulavam em torno da didática, da racionalidade, da disciplina, das práticas repressivas."

Ao prosseguir com a análise dos ditados, encontra-se, ainda, a temática do trabalho. $\mathrm{O}$ ditado intitulado "As profissões" explora diferentes ocupações profissionais existentes em torno de 1940, conforme transcrição: 
Sou lavrador, cavo a terra para depois semear. Eu pescador passo a vida na canoa sobre o mar. Medico as dores da vida sou a enfermeira. Sou mecânico perito não sei de melhor carreira. Operário desde cedo que começa o meu labor. Dos incêndios o bombeiro revela grande valor. Eu sou o médico excelente, tenho curas assombrosas. Na cozinha ao fogo ardente faço comidas gostosas. Comerciante zeloso não me afasto do balcão. Eu sou modista afamada, mas gozo como profissão. Sacerdote caridoso eu trabalho pela cruz de Cristo. Aprendiz de carpinteiro, eu sou o que foi Jesus. Toda profissão é nobre exercida com carinho, só o homem preguiçoso acha o trabalho mesquinho. (CADERNO DE SABATINAS).

O ditado acima enumera diferentes profissões, como as de pescador, enfermeira, mecânico, operário, bombeiro, médico, comerciante, modista, sacerdote e carpinteiro. Dentre as profissões, valoriza aspectos religiosos para o carpinteiro, mas, em oposição ao consenso geral, incluiu o sacerdócio como mais uma profissão entre as demais, o que causa estranhamento perante o discurso conhecido de vocação que envolve o papel de doação do sacerdote a serviço da comunidade. Em outro sentido, tal afirmação pode simplesmente estar referindo-se à profissão como sendo uma vocação, algo inato ao indivíduo.

No final do texto, há uma exaltação à profissão, e, em oposição, o adjetivo "preguiçoso" que nomeia aquele que não valoriza o trabalho.

Consoante a perspectiva da Escola Nova, "a ordenação do trabalho, a construção da nacionalidade, a modernização da sociedade e a democratização de um país" são tarefas de cunho pedagógico para a transformação do Brasil (SOUZA, 2009). Nas comemorações do dia do operário, fazia parte do programa as professoras proferirem palestras aos alunos exaltando a importância do trabalho. Tal situação pode ser observada na comemoração de 1942: "as professoras com os respectivos alunos dirigiram-se para as salas de aula, cada qual fez uma palestra, incutindo amor ao trabalho, mostrando a vantagem que traz ao seio da humanidade". (LIVRO DE ATAS - COMEMORAÇÕES CÍVICAS, 1942).

Nas atividades de escrita, ainda tem-se a redação e a cópia. Entende-se a redação como uma produção do aluno a partir de determinado tema, e a cópia como a reprodução de um texto já existente. A redação que compõe o caderno das sabatinas é intitulada "Probidade".

Alberto filho de um lavrador que estava sentado debaixo de uma árvore chorando amargamente. E passou um caçador vestido e disse: Porque chores tu rapaz. E o menino soluçando o papai me deu uma quantidade de dinheiro para pagar o farmacêutico. E o caçador tirando uma carteira que tinha muitas moedas de ouro e perguntou se era aquela a tua carteira e ele disse não, não é esta minha carteira. Então caçador, não tinha bastante dinheiro e era mais velha. O caçador tirando a outra carteira disse é esta é sua o menino disse é esta mesmo. E então o caçador deu outra de recompensa (CADERNO DE SABATINAS).

A produção traz elementos comumente encontrados na literatura infantil, como o caçador e as moedas de ouro, o que pode ser um indício da circulação de histórias no cotidiano escolar. Outro elemento a ser destacado são os valores. No texto, a aluna marca a ação de dizer a verdade como algo merecedor de recompensa. Já na atividade de cópia, o texto das figuras 2 e 3 apresenta-se como um diálogo. 
Figura 2 - Atividade de cópia

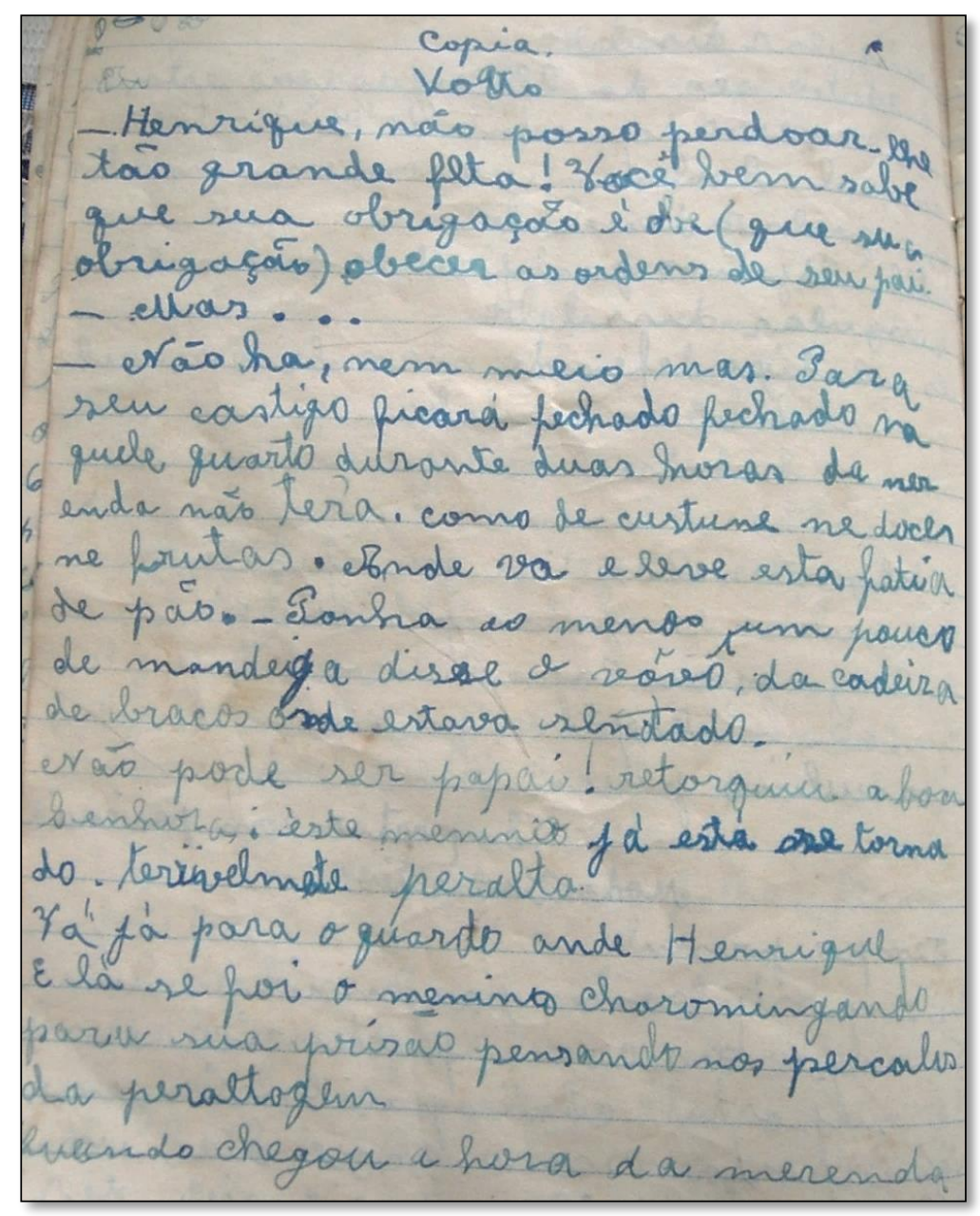

Fonte: Caderno de Sabatinas, APOR.

Figura 3: Atividade de cópia - continuação

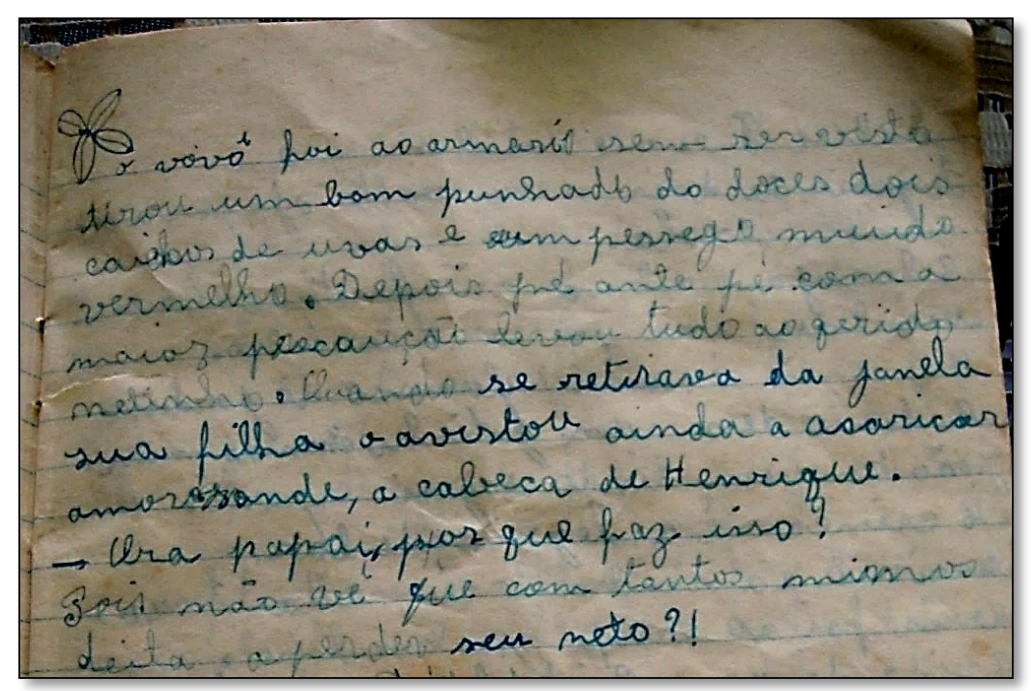

Fonte: Caderno de Sabatinas, APOR. 
A reprodução nas figuras 2 e 3, como os demais textos já apresentados, inclui uma noção formativa: o filho deveria obedecer ao pai, caso contrário mereceria o castigo; o avô é a figura que protege os netos, e a mãe é quem educa. Dessa forma, o texto era formativo no sentido de estipular os papéis de cada um, primeiro no texto e, por extensão, na comunidade.

Outra modalidade de escrita registrada foi a de compor frases: deveriam ser 20. No caso do caderno analisado, não foi possível saber se as frases foram criadas pela aluna, ou se fizeram parte do ditado. As frases são as seguintes:

Deus queira guardar paz em nosso lar. Saber é poder. Se Deus me acompanha eu volto. Salve Deus a minha casa. Depois de dois meses volto hoje para a minha escola. A laranja e a lima são fruta saborosas. Nicolau vai buscar o carrinho. O jasmim é o mais perfumoso do jardim. Antonio tem um gatinho chamado Mimi. João tem um lindo sagui esperto. A criança é a alegria do lar. Maria é a rainha do céu e da terra. Maria foi ao campo apanhar flores. A vida de Jesus Cristo foi muito triste. Um bom conselho vale mais que muitos castigos. O Brasil é um país rico e fértil. Trabalhemos pelo progresso do Brasil. O Brasil é um país rico [as últimas duas palavras são incompreensíveis]. O canário é um lindo passarinho amarelo. Anjo da guarda acompanha até de noite. Não poderá fugir das garras da raposa. (CADERNO DE SABATINAS).

As frases são no total de 21, o que indica que a aluna pode ter desconsiderado a frase cujas últimas palavras ficaram incompreensíveis. Quanto à construção das frases, é possível que seja produção da aluna ou ainda uma atividade de ditado ou cópia proposta pela docente, pois considera-se que os temas das frases fazem parte dos saberes que circulavam no período em voga no ensino primário.

Quanto às atividades de gramática, eram referentes à conjugação de verbos, seguidas da análise gramatical. A conjugação do verbo "escutar" foi realizada no modo indicativo: nos tempos presente, imperfeito, passado, futuro, condicional; no modo imperativo; no modo subjuntivo: nos tempos presente, imperfeito, futuro; no infinitivo: pessoal e impessoal; e no particípio. Em seguida, foi efetuada a análise gramatical das seguintes palavras: o, espetáculo, de, em, formigueiro, é, um, dos, mais, interessante. As classes gramaticais perscrutadas foram o artigo, substantivo, preposição, verbo, advérbio e adjetivo. Outro verbo conjugado foi "comer" e, das frases: "Partir a Porto Alegre" e "Cultivo a lavoura", a atividade consistia em conjugar os verbos em todos os tempos dos modos indicativo e subjuntivo.

Os conteúdos remetem aos saberes que seriam ensinados no quarto e quinto ano, em gramática e ortografia, conforme o Decreto $\mathrm{n}^{\circ} 8.020$ de 1939, que estipula o Programa mínimo a ser adotado pelas escolas primárias do Estado. As noções de ortografia e gramática deveriam ser desenvolvidas durante as aulas, sem indicação de horário para essas aulas.

O caderno de sabatinas era utilizado para fins de avaliação, e seria interessante saber quais os critérios usados para a sua realização, sobre a periodicidade (semanal, mensal, esporádica). Apesar de ser possível identificar as notas na maioria das sabatinas, optou-se por não enfocar o quantitativo das avaliações, mas sim destacar os temas que as permeiam, por compreender que as abordagens implícitas ou explícitas fazem parte das culturas escolares. É importante considerar que essa foi uma das formas de avaliar, e não a única, pois foi possível localizar na instituição livros de atas que tratam dos exames finais e, assim, pode-se perceber que outras provas/exames eram realizados para avaliar. 


\section{Considerações finais}

Os cadernos escolares constituem-se interessante fonte documental para a análise das culturas e práticas escolares no estudo de instituições escolares. No Colégio Nossa Senhora de Lourdes, serviram de suporte para avaliação nomeado como caderno de sabatinas e teve uma função de organização do cotidiano escolar e dos saberes, não sendo sua única finalidade a utilização para avaliação. Foi possível verificar também o uso de cadernos de desenho e caligrafia, por exemplo, mas podem ter sido adotados outros cadernos e outros usos não identificados na pesquisa.

O caderno em questão, de sabatinas do ensino primário, traz indícios dos modos de apropriação das formas de avaliar da instituição em que são utilizados exercícios tais como ditado, redação, cópia, escrita de frases, conjugação verbal, análise gramatical e questionários de perguntas e respostas. Isso indica também uma aproximação com as práticas de escrita nessa instituição, e a centralidade da escrita na disseminação dos demais saberes, aliada à caligrafia, à ortografia e à gramática. As marcas de correção ortográfica e a utilização de outra cor para a escrita da professora caracterizam práticas utilizadas pela docente na intervenção e correção da avaliação.

Os exercícios escolares trazem indícios não só dos saberes, mas também dos valores morais e das condutas estimuladas no cotidiano escolar e que fizeram parte das culturas escolares do Colégio Nossa Senhora de Lourdes no ensino primário na década de 40 do século XX. Nesse contexto, foi possível identificar, pela análise das memórias, que foram características valorizadas o respeito, a disciplina e o silêncio. Fica implícito também o que se deve entender por família e seus papéis sociais, a importância da religião católica, da saúde, da higiene, da valorização do nacional, do trabalho e de comportamentos esperados dentro e fora do ambiente escolar.

Não se pode desconsiderar que as práticas escolares são permeadas pelos programas, pelos decretos, pelas ideias pedagógicas em circulação e também pelas organizações da congregação com relação ao corpo docente, as oportunidades de formação de professoras, espaços físicos e materiais. Por fim, compreender que além do já citado, o ambiente escolar oportuniza um espaço de usos criativos e inventivos, permeados pelas culturas escolares.

\section{Referências}

ARRIADA, Eduardo. TAMBARA, Elomar Antonio Callegaro. A cultura escolar material, a modernidade e a aquisição da escrita no Brasil no século XIX. Educação, Porto Alegre, v.35, n.1, jan./abr. 2012. p. 73-88. Disponível em: < file://C:/Users/hp/Downloads/10352-39608-1PB.pdf>. Acesso em 05 mar. 2017.

BELUSSO, Gisele. Colégio Nossa Senhora de Lourdes, Farroupilha, RS: histórias de sujeitos e práticas (1922-1954). 2016. 237 p. Dissertação (Mestrado em Educação) - Universidade de Caxias do Sul, Programa de Pós-Graduação em Educação, Caxias do Sul, 2016.

BRESOLIN, EMA. Pedagogia carlista-scalabriniana no contexto sócio-educacional de nosso tempo. 1998. Dissertação (Mestrado em Educação) - Pontifícia Universidade Católica do Rio Grande do Sul, Programa de Pós-Graduação em Educação, Porto Alegre, 1998. 
CERTEAU, Michel de. A invenção do cotidiano: artes de fazer. Tradução de Ephraim Ferreira Alves. 2.ed. Rio de Janeiro: Vozes, 1994.

CHARTIER, Anne-Marie. Fazeres ordinários da classe: uma aposta para a pesquisa e para a formação.Educação e Pesquisa, São Paulo, v.26, n.2, jul./dez. 2000. p. 157-168. Disponível em: 〈http://www.scielo.br/pdf/ep/v26n2/a11v26n2.pdf>. Acesso em: 18 ago. 2015.

Os cadernos escolares: organizar os saberes, escrevendo-os. Revista de EducaçãoPública, Cuiabá, v.16, n. 32, p.13-33, set./dez.2007. Disponível em:<file:///C:/Users/User/Downloads/542-847-1-PB\%20.pdf>. Acesso em 10 jan. 2017.

Ensinar a ler e escrever, entre teoria e prática. Palestra apresentada na V Semana da Educação, da Fundação Victor Civita. São Paulo, 20 de outubro de 2010. Disponível em: <http://acervo.novaescola.org.br/pdf/texto-anne-marie-chartier.pdf>. Acesso em: 13 jul. 2016.

CHARTIER, Roger. A história cultural: entre práticas e representações. Tradução de Marcia Manuela Galhardo. 2. ed. Lisboa: Difusão Editorial, 2002.

Leituras e Leitores na França do Antigo Regime. Trad. de Álvaro Lorencini. São Paulo: UNESP, 2004.

CORDOVA, Tania. Redações, cartas e composições livres: o caderno escolar como objeto da cultura material da escola (Lages/SC - 1935). História da Educação. v.20, n. 49, mai./ago. 2016. P. 209-226. Disponível em: < http://www.scielo.br/pdf/heduc/v20n49/2236-3459-heduc20-49-00209.pdf>. Acesso em: 05.mar.2017.

CUNHA, Maria Teresa Santos Cunha; SOUZA, Flávia de Freitas. Viver e escrever cadernos e escritas ordinárias de um professor catarinense ( Sec XX). Florianópolis: Insular, 2015.

Acervos Pessoais de Educadores: Do traçado manual ao registro digital. In: REUNIÃO CIENTÍFICA DA ANPED, XI. 2016, Curitiba. Anais da XI ANPED sul. Curitiba, UFPR, 2016. Disponível em: <http://www.anpedsul2016.ufpr.br/wpcontent/uploads/2015/11/Eixo-1-Hist\%C3\%B3ria-da-Educa\%C3\%A7\%C3\%A3o.pdf>. Acesso em: 12 de jan. 2016.

DI SIERVI, Maria de Lourdes. Pão, educação e trabalho: Orfanato Cristovão Colombo e a educação profissionalizante de crianças na cidade de São Paulo (1895-1930). 2002. Dissertação (Mestrado em História) - Pontifícia Universidade Católica de São Paulo, Programa de Pósgraduação em História, São Paulo, 2002.

FAGGION, Carmen Maria; LUCHESE, Terciane Ângela. Bilinguismo e escolarização na Região Colonial Italiana do Rio Grande do Sul, 1930 - 1960. In: SILVA, Sidney de Souza (Org.). Línguas em contato: cenários de bilinguismo no Brasil. Campinas, SP: Pontes, 2011, p. 197-224.

FERNANDES, Rogério. Um marco no território da criança: o caderno escolar. In: Mignot, Ana Chrystina Venancio. Cadernos à vista: escola, memória e cultura escrita. Rio de Janeiro: EdUERJ, 2008. p.49 - 68. 
FONSECA, Nelma Marçal Lacerda Fonseca; REIS, Diogo Alves de Faria; GOMES, Maria Laura Magalhães; FARIA FILHO, Luciano Mendes de. O caderno de uma professora-aluna e as propostas para o ensino de aritmética na escola ativa (Minas Gerais, década de 1930). História da Educação, Porto Alegre, v.18, n. 42, p. 9-35, jan./abr.2014. Disponível em:<http://www.scielo.br/pdf/heduc/v18n42/02.pdf>. Acesso em 01 fev.2017.

FROSI, Vitalina Maria e MIORANZA, Ciro. Imigração italiana no nordeste do Rio Grande do Sul: processos de formação e evolução de uma comunidade ítalo-brasileira. $2^{\mathrm{a}}$ ed. Caxias do Sul, RS: EDUCS, 2009.

FROSI, Vitalina Maria; MIORANZA, Ciro. (1983). Dialetos italianos. Caxias do Sul, RS: EDUCS, 1983.

GIOLO, Jaime. Estado, Igreja e Educação no RS da Primeira República. 1997. 429 p. Tese (Doutorado em Educação) - Faculdade de Educação da Universidade de São Paulo, Programa de Pós-graduação em Educação, São Paulo, 1997.

HÉRBRARD, Jean. Por uma bibliografia material das escritas ordinárias o espaço gráfico do caderno escolar ( França - séculos XIX e XX). Tradução de Laura Hansen. Revista Brasileira de História da Educação. n.1. p.115-141, jan/jun. 2001. Disponível em: <http://www.rbhe.sbhe.org.br/index.php/rbhe/article/view/277>. Acesso em 01 fev.2017.

JULIA, Dominique. A cultura escolar como objeto historiográfico. Tradução de Gizele de Souza. Revista Brasileira de História da Educação, n.1, p.9-44, jan./jun. 2001. Disponível em: <http://www.rbhe.sbhe.org.br/index.php/rbhe/article/view/273>.Acesso em: 15 abr. 2015.

LEONEL FRANCA, S. J. O método pedagógico dos jesuítas: o RatioStudiorum. Rio de Janeiro: $\quad$ Agir, $1952 . \quad$ Disponível em: http://www.histedbr.fe.unicamp.br/navegando/fontes_escritas/1_Jesuitico/ratio\%20studiorum. htm>. Acesso em: 26 jun. 2016.

MENESES, Ulpiano T. Bezerra de. Memória e cultura material: documentos pessoais no espaço público. Estudos Históricos.v.21, 1998. P. 89-103. Disponível em: < http://bibliotecadigital.fgv.br/ojs/index.php/reh/article/view\%20File/2067/1206>. Acesso em 05 mar.2017.

MOGARRO, Maria João. Cultura material e modernização pedagógica em Portugal ( séculos XIX - XX). Educatio Siglo XXI, v. 28, n.2, 2010. p. 89-114. Disponível em: < http://repositorio.ul.pt/bitstream/10451/12308/1/Cultura_Material_e_moderniza\%C3\%A7\%C 3\%A3o_pedag\%C3\%B3gica.pdf>. Acesso em 05 mar. 2017.

MIGNOT, Ana Cristina Venancio (Org.). Cadernos à vista: escola, memória e cultura escrita. Rio de Janeiro: Uerj, 2008.

NAZARIO, Celina Lessa. Diálogo: mestre e discípulo uma leitura teológica da Pedagogia do Oprimido de Paulo Freire. 2011. Dissertação (Mestrado em Teologia) - Pontifícia Universidade Católica do Rio Grande do Sul, Programa de Pós-graduação em Teologia /Porto Alegre, 2011. Disponível em<http://repositorio.pucrs.br/dspace/handle/10923/5286.> Acesso em: 13 mai. 2015. 
OLIVEIRA, Lúcia Helena. Memória e História Educacional: o papel do Colégio Santa Teresa no processo escolar de Ituiutaba no Triângulo Mineiro-MG (1939-1942). 2003. $149 \mathrm{f}$. Dissertação (Mestrado em Educação). Universidade Federal de Uberlândia, Programa de PósGraduação em Educação, Uberlândia, 2003.

. Educação Scalabriniana no Brasil. Tese (Doutorado em Educação) Pós-Graduação em Educação, Universidade de Campinas/SP, 2009. Disponível em: < http://www.bibliotecadigital.unicamp.br/document/?code $=000469611>$. Acesso em: 21 nov 2014.

PAZ, Valéria Alves. História do Colégio São Carlos de Caxias do Sul, Rio Grande do Sul, Rio Grande do Sul (1936-1971). 2013. 157 p. Dissertação (Mestrado em Educação) Programa de Pós-Graduação em Educação, Universidade de Caxias do Sul, 2013. Disponível em: <https://repositorio.ucs.br/jspui/bitstream/11338/470/1/Dissertacao\%20Val\%C3\%A9ria \%20Alves\%20Paz.pdf>. Acesso em: 21 out. 2014.

PERES, Eliane. Currículo e práticas escolares da escola primária gaúcha no período de implantação da escola graduada e da institucionalização da modernidade pedagógica ( 19091959). In: GRAZZIOTIN, Luciane Sgarbi Santos; BITTENCOURT, Dóris Almeida. Colégios Elementares e grupos escolares no Rio Grande do Sul: memórias e cultura escolar - séculos XIX e XX. São Leopoldo: Oikos, 2016. p. 30 - 64.

POLETTO, Julia Tomedi. Colégio Sagrado Coração de Jesus, Bento Gonçalves/RS: Processo Identitário e cultura escolar compondo uma história. 2014. 212p. Dissertação (Mestrado em Educação) - Universidade de Caxias do Sul, Programa de Pós-Graduação em Educação, Caxias do Sul, 2014.

SIGNOR, Lice Maria. Irmãs Missionárias de São Carlos, Scalabrinianas - 1895 - 1934. Brasília: CSEM, 2005.

2007.

Irmãs Missionárias de São Carlos, Scalabrinianas - 1934-1971. Brasília: CSEM,

. João Batista Scalabrini e a imigração italiana: um projeto sócio-pastoral. Porto Alegre: Palotti, 1984.

SOUZA, Rosa Fátima de. História da cultura material escolar: um balanço inicial. In: Culturas escolares, saberes e práticas educativas: itinerários históricos. BENCOSTTA, Marcus Levy (Org.). São Paulo: Cortez, 2007. p.163-189.

Alicerces da Pátria: história da escola primária no estado de São Paulo (1890-1976). Campinas, SP:Mercado das Letras, 2009.

SOUZA, Wlaumir Doniseti. Anarquismo, Estado e pastoral do imigrante. Das disputas ideológicas pelo imigrante aos limites da ordem: o caso Idalina. São Paulo: Editora UNESP, 2000.

TRENTIN, Ortenila Dileta M. Emancipação de Nova Vicenza, Farroupilha. 2002. 88 f. Monografia (Especialização em História), Universidade de Caxias do Sul, 2002. 
VIDAL, Diana Gonçalves. No interior da sala de aula: ensaio sobre cultura e prática escolares. Currículo sem Fronteiras, v.9, n.1, p.25-41, jan./jun. 2009. Disponível em < http://www.curriculosemfronteiras.org.> Acesso em: 09 abr. 2015.

; ESTEVES, Isabel de Lourdes. Modelos caligráficos concorrentes: as prescrições para a escrita na escola primária paulista (1910-1940). In: PERES, E.; TAMBARA, E.(Orgs). Livros Escolares e ensino da leitura e da escrita no Brasil ( séculos XIX-XX).Pelotas: Publicações Seiva, 2003. p.117-138

VIÑAO FRAGO, Antonio. Os cadernos escolares como fonte histórica: aspectos metodológicos e historiográficos. In: Mignot, Ana Chrystina Venancio. Cadernos à vista: escola, memória e cultura escrita. Rio de Janeiro: EdUERJ, 2008. p.15-33.

\section{Entrevistas}

DORIGON, Dino José. Dorigon. Entrevista concedida a Gisele Belusso. Farroupilha, 10 de maio de 2016. Entrevista.

NORO, Alice T. Entrevista concedida a Gisele Belusso. Farroupilha, 12 de novembro de 2015. Entrevista.

RASERA, Odete. Entrevista concedida a Gisele Belusso. Farroupilha, 12 de novembro de 2015. Entrevista.

TARTAROTTI, Raul Pedro Tartarotti. Entrevista concedida a Gisele Belusso. Farroupilha,20 de agosto de 2015. Entrevista.

\section{Documentos}

CADERNO DE SABATINAS - Acervo pessoal de Odete Rasera.

LIVRO DE ATAS DE COMEMORAÇÕES CÍVICAS, 1942 - Arquivo do Colégio Nossa Senhora de Lourdes, Farroupilha/RS.

Decreto $\mathrm{n}^{\circ} 8020$, de 29 de novembro de 1939 - Aprova o programa mínimo a ser adotado nas escolas primárias do Estado. Disponível em: 〈https://repositorio.ufsc.br/>. Acesso em: 16 abr. 2016. 